\title{
Factors Associated with Direct Health Care Costs Among Patients with Migraine
}

\author{
Machaon Bonafede, PhD, MPH; Qian Cai, MS, MSPH; Katherine Cappell, PhD; \\ Gilwan Kim, PharmD, MS; Sandhya J. Sapra, PhD; Neel Shah, PhD; Katherine Widnell, MD, PhD; \\ Paul Winner, PhD; and Pooja Desai, PhD
}

\begin{abstract}
BACKGROUND: Migraine imposes substantial economic burden on patients and the health care system. Approximately $18 \%$ of women and $6 \%$ of men suffer from migraine in the United States. This is a heterogeneous group, and little data are available to evaluate factors associated with migraine costs.
\end{abstract}

OBJECTIVE: To evaluate characteristics associated with high costs among commercially insured patients with migraine.

METHODS: This retrospective analysis identified patients with migraine in the Truven Health MarketScan Research Databases between January 2008 and June 2013. Patients were required to have 12 months continuous enrollment before and after migraine diagnoses and/or migraine-specific medications (index date). Patients with costs greater than the top 25th percentile of all-cause costs during the 12-month post-index period were classified into the upper quartile (UQ) cohort. Multiple logistic regression was used to evaluate demographic and clinical factors associated with being in the UQ cohort, and generalized linear models were used to estimate the incremental costs by select factors after controlling for other covariates.

RESULTS: In the total population, 857,073 patients (mean [SD] age: 43.2 [12.5] years), were included, with $83.2 \%$ females. Average post-index annual all-cause costs were $\$ 13,045(S D=\$ 25,328)$ with the top 25th percentile of costs at $\$ 14,120$. Overall, $44.4 \%$ and $54.8 \%$ of patients had $\geq 1$ pre-index claim for opioids and triptans, respectively. Patients with $\geq 2$ migraine-related emergency room visits were twice as likely to be in the UQ cohort $(\mathrm{OR}=2.13,95 \% \mathrm{Cl}=2.02-2.25 ; P<0.05)$ and incurred $\$ 3,125$ incremental all-cause costs compared with those with $<2$ visits. Patients who visited a neurologist were $33.0 \%$ more likely to be in the UQ cohort and had significantly higher adjusted all-cause costs $(\$ 11,794$ vs. $\$ 9,868, P<0.05)$. Opioid users had a $1.5-3$ times increased likelihood of being in the UQ cohort $(P<0.05)$; adjusted all-cause annual costs ranged from $\$ 8,888(95 \% \mathrm{Cl}=\$ 8,862-\$ 8,914)$ for nonusers to $\$ 15,210(95 \%$ $\mathrm{Cl}=\$ 15,113-\$ 15,307)$ for high users (7+ claims). Patients having $7+$ triptan claims were 1.2 times as likely to be in the UQ cohort compared with nonusers, with estimated costs of $\$ 11,517(95 \% \mathrm{Cl}=\$ 11,438-\$ 11,596)$ for high users and $\$ 10,753(95 \% \mathrm{Cl}=\$ 10,717-\$ 10,790)$ for nonusers.

CONCLUSIONS: Results suggest that certain modifiable factors, such as increased acute medication use (opioids and triptans) and more migrainerelated emergency room visits are associated with higher all-cause health care costs for patients with migraine. These findings could be used to identify patients who require early intervention, enhanced symptoms monitoring, and appropriate disease management. Future studies could examine the effect of disease severity on health resource utilization and costs using survey or medical record data.

J Manag Care Spec Pharm. 2017;23(11):1169-76

Copyright $\odot 2017$, Academy of Managed Care Pharmacy. All rights reserved.

\section{What is already known about this subject}

Migraine is the most common neurological disorder in the United States and accounts for approximately $\$ 14$ billion in direct and indirect costs annually.

Migraine affects about 38 million people in the United States, including 4 million chronic headache sufferers

Estimates from the International Burden of Migraine Study suggest that the average 3-month headache-related costs were about $\$ 1,036$ and $\$ 383$ for chronic and episodic migraine, respectively.

\section{What this study adds}

This study provides patient characteristics readily available to payers to identify patients who may benefit from closer monitoring and interventions for migraine.

Patients with 2 or more migraine-related emergency room visits, opioid use, and triptan overuse were associated with higher allcause costs than those without.

There was a strong association between presence of a migrainerelated neurologist visit and direct all-cause costs, but this may be a reflection of adjusted disease severity.

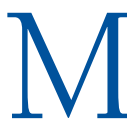
igraine is a common, debilitating neurological disorder primarily characterized by intense and recurrent headaches, which can last from 4 to 72 hours. Typically, the pain is unilateral, pulsating, and often associated with nausea, vomiting, photophobia, or phonophobia., ${ }^{1,2}$ Based on the frequency of headache, migraine is classified as episodic or chronic migraine, with chronic migraine defined as $\geq 15$ headache days per month for more than 3 months and having features of migraine headache on at least 8 days per month. ${ }^{2}$ An estimated 38 million people in the United States experience migraine headaches, and they are 3 times as prevalent among women as men. ${ }^{3,4}$ Of the patients that experience migraine, approximately 4 million suffer from chronic daily migraine. ${ }^{3}$ Although migraine may occur at any age, it most often occurs during peak employment years (ages 25-55 years). ${ }^{5}$

Treatment guidelines for the management of migraine recommend acute and preventive treatments based on severity and frequency of headache, along with patient characteristics and preferences. ${ }^{6-8}$ Acute medications include migraine-specific 
medications (ergotamines and triptans) and nonspecific medications (e.g., nonsteroidal anti-inflammatory drugs, opioids, and combination analgesics with tramadol). Current migraine prophylactic medications include a variety of medications indicated for the management of other chronic illness but have been repurposed for migraine (e.g., topiramate, selected beta blockers, calcium channel blockers, and tricyclic antidepressants). ${ }^{9,10}$ The use of available migraine prophylactic medications is limited by side effects and lack of efficacy, which leads to a large unmet need for newer targeted therapies. ${ }^{11-13}$

Because of the observed poor adherence to acute and preventive migraine medications, ${ }^{14}$ migraine patients experience frequent attacks, which may require more health care resource utilization, especially in terms of emergency room (ER) visits and acute medication use., ${ }^{3,15-20}$ In a National Hospital Ambulatory Medical Care survey, 2.9\%-3.1\% of the total ER visits in 2007 and 2009-2010 were related to headache/ migraine. ${ }^{21,22}$ Studies have shown that opioids are prescribed more frequently for acute migraine, and the overuse of opioids is a major factor that contributes to increased resource use in patients with migraine. ${ }^{18,23,24}$ Existing evidence suggests that opioid abuse may exacerbate existing conditions, leading to increased attacks as well as longer ER stays or repeat ER visits. ${ }^{25}$

Chronic and episodic migraine impose substantial economic burden on the U.S. health care system. ${ }^{26}$ In a modelbased study, the annual economic burden of migraine in the United States was estimated to be $\$ 14$ billion per year, which included direct costs as well as costs incurred due to loss of productivity. ${ }^{27}$ Hawkins et al. (2008) estimated that incremental total per-patient-per-year health care expenditures were $\$ 3,275$ (in 2016 U.S. dollars) higher for patients with migraine than matched controls. ${ }^{28}$ The International Burden of Migraine Study (2011) estimated that the average 3-month headacherelated direct costs for patients with chronic migraine and episodic migraine were at $\$ 1,036$ and $\$ 383$, respectively, in the United States. ${ }^{20}$ More recently, a web-based survey study (2016) showed that the mean total annual headache-related costs were significantly greater for patients with chronic migraine than those with episodic migraine ( $\$ 8,243$ vs. $\$ 2,649 ; P<0.001){ }^{26}$

Characterization of factors associated with patients in higher quartiles of costs is critical, since this could help with delivering optimal care in a targeted manner. A 2015 study suggested that patients in the top 20\% of total health care costs can be considered as high-cost patients. ${ }^{29}$ Several other studies have shown that age, insurance status, presence of psychiatric symptoms, and use of prophylactic medications and acute medications such as triptans were associated with health care utilization and costs among migraine patients. ${ }^{15,30-33}$ However, little is known about characteristics that could aid in the identification of migraine patients who have higher than average expenditures. Therefore, the objective of this study was to identify patient characteristics associated with high costs among commercially insured patients with migraine in the United States.

\section{Methods}

\section{Data Source}

Data on health care costs and patient characteristics were extracted from the Truven Health MarketScan Commercial and Medicare Supplemental Databases. The Commercial Database contains the pharmacy and medical (inpatient and outpatient) claims of employees and their dependents, and the Medicare Supplemental Database profiles the health care experience of individuals with Medicare supplemental insurance paid for by employers. Both databases provide detailed outcomes measures, including resource utilization and associated costs (inpatient and outpatient) for approximately 35 million individuals covered annually by a geographically diverse group of self-insured employers and private insurance plans across the United States.

All study data were accessed with protocols compliant with U.S. patient confidentiality requirements, including the Health Insurance Portability and Accountability Act of 1996 regulations. Since this study used only statistically deidentified patient records, it was exempted from institutional review board approval.

\section{Study Design}

This study was a retrospective, observational claims database analysis to evaluate the factors associated with higher total health care costs in the 12-month follow-up period among patients with migraine in a large privately insured U.S. population. Eligible patients were selected from the MarketScan databases from January 1, 2008, through June 30, 2013.

\section{Study Population}

Patients were considered as having migraine if they met at least 1 of the following criteria: (a) at least 1 inpatient or 1 ER claim with a diagnosis code in any position for migraine (International Classification of Diseases, Ninth Revision, Clinical Modification [ICD-9-CM] diagnosis 346.xx); (b) at least 2 outpatient claims (7-180 days apart) with a diagnosis of migraine; (c) at least 1 outpatient claim with a migraine diagnosis plus at least 1 outpatient pharmacy claim for a triptan, ergotamine, or topiramate (7-180 days apart); or (d) at least 2 outpatient pharmacy claims for a triptan or ergotamine (7-180 days apart) between January 1, 2008, and June 30, 2013. For each patient, the earliest date on which the patient met at least 1 of the these criteria was set as the index date; this approach included incident and prevalent migraine cases at index.

Patients were also required to have continuous enrollment with medical and pharmacy coverage for 12 months before (pre-index period) and after the index date (post-index period). Patients aged $<18$ years on the index date or who had a 


\section{FIGURE 1 Patient Identification Flowchart}

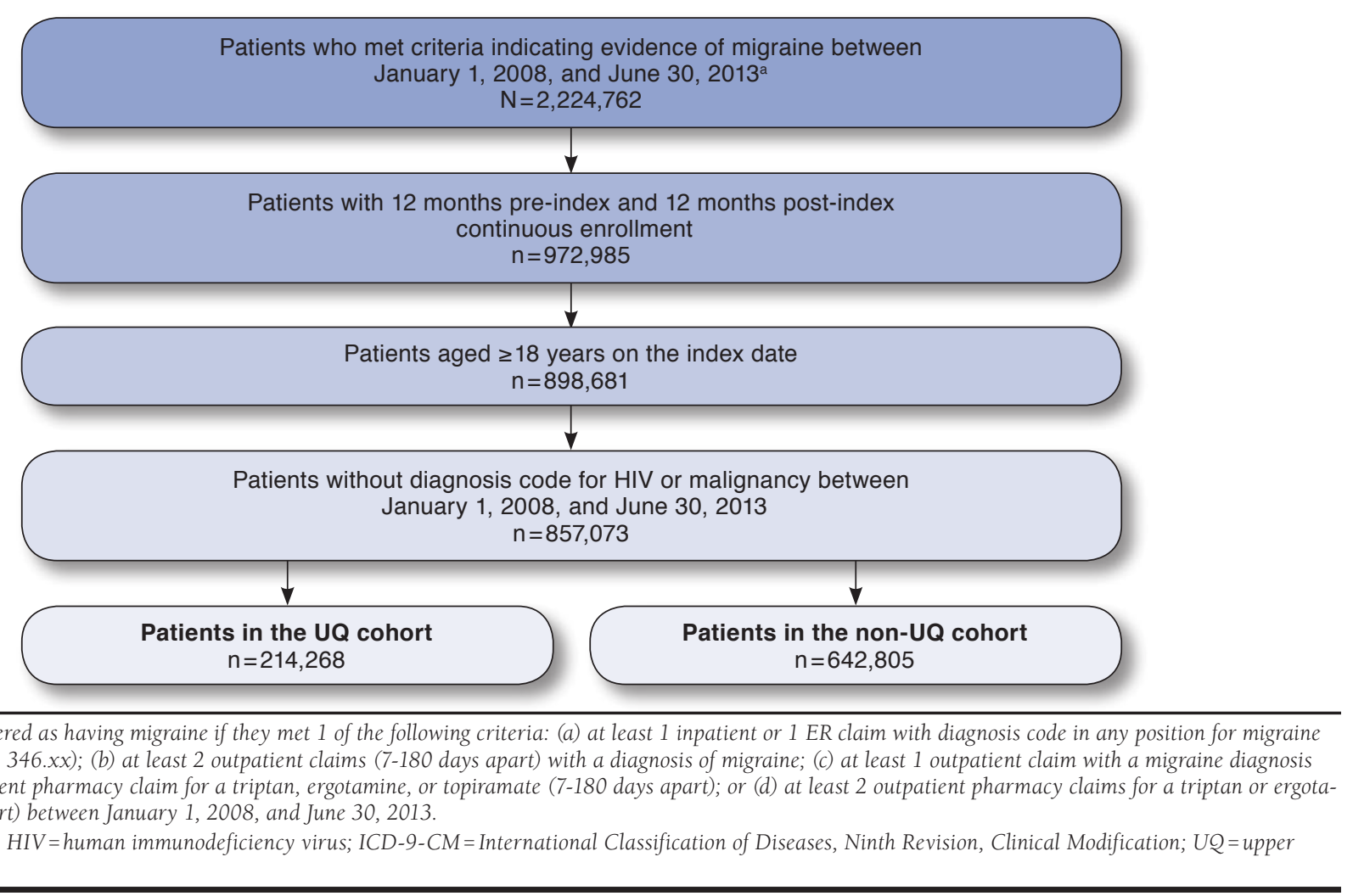

diagnosis of HIV (ICD-9-CM 042.xx-044.99) or malignancy (ICD-9-CM 140.xx-172.99, 174.xx-195.99, 200.xx-208.99) at any point during the study period were excluded.

Health care costs were expressed in 2014 U.S. dollars, adjusted using the medical care component of the Consumer Price Index. All-cause health care costs were determined by summing the paid amount, including plan paid and patient paid, from medical and pharmacy services. Patients who had all-cause costs in the top 25th percentile were classified in the upper quartile (UQ) cohort, and the rest of the patients were classified into the non-UQ cohort.

\section{Study Variables}

Patient demographics such as age, gender, geographic region (U.S. Census division), and primary payer were measured on the index date. Clinical characteristics were measured in the 12-month pre-index period and included the Deyo adaptation of the Charlson Comorbidity Index (DCI), an indicator of overall disease burden for the occurrence of at least 1 of 17 comorbid conditions identified using the ICD-9-CM coding manual. ${ }^{34}$ In addition, general comorbid conditions (e.g., anxiety, asthma, cardiac arrhythmia, depression, epilepsy, hypertension, myocardial infarction, osteoarthritis, chronic pain, and stroke) and use of migraine-related medications (defined as patients using prophylactic medications only, acute medications only, prophylactic and acute medications, and no prophylactic or acute migraine medications) were also assessed. Other factors including neurologist visits, at least 2 migraine-related ER visits, and number of claims for triptans and opioids were also assessed in the 12-month pre-index period.

\section{Statistical Analysis}

All study variables, including demographic and clinical characteristics, were analyzed descriptively between study cohorts. Categorical variables were summarized by frequency and percentages, and continuous variables were reported as means and standard deviations (SD). To compare the differences in patient characteristics and study outcome measures between patients in upper and lower quartile cost cohorts, chi-square tests were used for categorical variables and Student's t-tests were used for continuous variables.

Multivariable logistic regression analyses were conducted to evaluate factors associated with all-cause costs for migraine patients in the UQ cohort. Generalized linear models (GLMs) were used to estimate incremental all-cause costs for patients with a neurologist visit, at least 2 migraine-related ER visits, 


\begin{tabular}{|c|c|c|c|}
\hline & $\begin{array}{l}\text { Non-UQ Cohort } \\
(\mathrm{n}=642,805)\end{array}$ & $\begin{array}{c}\text { UQ Cohort } \\
(n=214,268)\end{array}$ & $P$ Value \\
\hline Age, mean (SD) & $42.3(12.4)$ & $45.90(12.7)$ & $<0.001$ \\
\hline \multicolumn{4}{|l|}{ Age group, years, n (\%) } \\
\hline $18-34$ & $178,092(27.7)$ & $42,679(19.9)$ & $<0.001$ \\
\hline $35-49$ & $272,881(42.5)$ & $84,780(39.6)$ & \\
\hline $50+$ & $191,832(29.8)$ & $86,809(40.5)$ & \\
\hline Female, n (\%) & $531,370(82.7)$ & $181,431(84.7)$ & $<0.001$ \\
\hline \multicolumn{4}{|l|}{ Region, n (\%) } \\
\hline Northeast & $107,939(16.8)$ & $33,642(15.7)$ & $<0.001$ \\
\hline North Central & $148,917(23.2)$ & $52,178(24.4)$ & \\
\hline South & $250,114(38.9)$ & $83,095(38.8)$ & \\
\hline West & $125,916(19.6)$ & $42,272(19.7)$ & \\
\hline Unknown & $9,919 \quad(1.5)$ & $3,081 \quad(1.4)$ & \\
\hline Commercial, n (\%) & $624,902(97.2)$ & $201,559(94.1)$ & $<0.001$ \\
\hline Capitation, n (\%) & $113,198(17.6)$ & $34,723(16.2)$ & $<0.001$ \\
\hline DCI, mean (SD) & $0.16(0.45)$ & $0.61(1.01)$ & $<0.001$ \\
\hline \multicolumn{4}{|c|}{ Comorbid conditions, $\mathrm{n}(\%)$} \\
\hline Anxiety & $61,823 \quad(9.6)$ & $43,162(20.1)$ & $<0.001$ \\
\hline Asthma & $37,829 \quad(5.9)$ & $31,689(14.8)$ & $<0.001$ \\
\hline Cardiac arrhythmia & $14,772 \quad(2.3)$ & $22,262(10.4)$ & $<0.001$ \\
\hline Depression & $76,209(11.9)$ & $62,880(29.3)$ & $<0.001$ \\
\hline Epilepsy & $6,793 \quad(1.1)$ & $8,967(41.8)$ & $<0.001$ \\
\hline Hypertension & $105,051(16.3)$ & $75,878(35.4)$ & $<0.001$ \\
\hline Myocardial infarction & $262(0.04)$ & $2,104 \quad(1.0)$ & $<0.001$ \\
\hline Osteoarthritis & $42,803 \quad(6.7)$ & $55,038(25.7)$ & $<0.001$ \\
\hline Chronic pain & $117,544(18.3)$ & $99,658(46.5)$ & $<0.001$ \\
\hline Stroke & $6,654 \quad(1.0)$ & $13,040 \quad(6.1)$ & $<0.001$ \\
\hline \multicolumn{4}{|l|}{ Medication use, n (\%) } \\
\hline $\begin{array}{l}\text { Prophylactic } \\
\text { medication only }\end{array}$ & $26,627 \quad(4.1)$ & $6,301 \quad(2.9)$ & \multirow[t]{2}{*}{$<0.001$} \\
\hline Acute medication only & $371,539(57.8)$ & $113,355(52.9)$ & \\
\hline $\begin{array}{l}\text { Prophylactic and acute } \\
\text { medication }\end{array}$ & $130,384(20.3)$ & $65,589(30.6)$ & \\
\hline $\begin{array}{l}\text { Neither prophylactic nor } \\
\text { acute medication }\end{array}$ & $114,255(17.8)$ & $29,023(13.6)$ & \\
\hline \multicolumn{4}{|c|}{ Proxy severity measures, n (\%) } \\
\hline $\begin{array}{l}\geq 2 \text { migraine-related } \\
\text { ER visits }\end{array}$ & $3,031 \quad(0.5)$ & $4,640 \quad(2.2)$ & $<0.001$ \\
\hline Neurologist visits & $121,667(18.9)$ & $64,244(30.0)$ & $<0.001$ \\
\hline \multicolumn{4}{|c|}{ Number of triptan claims, $\mathrm{n}(\%)$} \\
\hline 0 & $273,458(42.5)$ & $113,582(53.0)$ & \multirow{4}{*}{$<0.001$} \\
\hline $1-3$ & $256,759(39.9)$ & $64,300(30.0)$ & \\
\hline $4-6$ & $58,169 \quad(9.1)$ & $16,008 \quad(7.5)$ & \\
\hline $7+$ & $54,419 \quad(8.5)$ & $20,378 \quad(9.5)$ & \\
\hline \multicolumn{4}{|c|}{ Number of opioid claims, n (\%) } \\
\hline 0 & $398,448(62.0)$ & $78,353(36.6)$ & \multirow{4}{*}{$<0.001$} \\
\hline $1-2$ & $151,702(23.6)$ & $52,189(24.4)$ & \\
\hline $3-6$ & $50,712 \quad(7.9)$ & $32,242(15.1)$ & \\
\hline $7+$ & $41,943 \quad(6.5)$ & $51,484(24.0)$ & \\
\hline
\end{tabular}

$D C I=$ Deyo-Charlson Comorbidity Index; ER=emergency room; $S D=$ standard deviation; $U Q=$ upper quartile of cost. and use of an opioid or triptan (based on number of prescription claims) in the pre-index period, after controlling for relevant demographic characteristics (age, gender, plan type, region); comorbid conditions (DCI score and baseline comorbidities); and medications of interest (prophylactic, acute, prophylactic and acute, and no prophylactic or acute migraine medications). Multicollinearity of variables was checked using a correlation test; diagnostic tests were conducted to evaluate the distribution of cost data; and GLMs with log link function and gamma distribution were used to generate the incremental costs attributable to select factors. A $P$ value of $<0.05$ was considered statistically significant. All data analyses were conducted using SAS version 9.4 (SAS Institute, Cary, NC).

\section{Results}

A total of 857,073 patients met the criteria and were included in the study (Figure 1). Average all-cause costs in the post-index period were $\$ 13,045(\mathrm{SD}=\$ 25,328)$ per patient. Among the 857,073 patients, the mean migraine-related cost was $\$ 1,887$ $(\mathrm{SD}=\$ 3,903)$ in the post-index period, accounting for $14.5 \%$ of the all-cause costs $(\$ 13,045)$. The median of the all-cause costs was $\$ 6,362$, with the top 25 th percentile of all-cause costs at $\$ 14,120$ and the lower quartile at $\$ 2,918$; therefore, patients with all-cause costs equal to or greater than $\$ 14,120$ were classified into the UQ cohort $(n=214,268)$, and those lower than this threshold were classified into the non-UQ cohort $(n=642,805)$. The mean of the migraine-related costs in the UQ cohort was $\$ 3,666(\mathrm{SD}=\$ 7,054)$ and was $\$ 1,294$ $(\mathrm{SD}=\$ 1,522)$ for the non-UQ cohort.

\section{Patient Characteristics}

On average, patients were aged $43.2(\mathrm{SD}=12.5)$ years, and 83.2\% were female. Among patients in the UQ cohort, 2.1\% $(n=11,076)$ had a diagnosis for chronic migraine in the pre-index period; $1.3 \%(n=14,778)$ of patients in the nonUQ cohort had chronic migraine in the pre-index period. Compared with the non-UQ cohort, those in the UQ cohort were significantly older ( 42.3 vs. 45.9 years; $P<0.001)$ and had a significantly higher percentage of females ( $82.7 \%$ vs. $84.7 \%$; $P<0.001)$. The majority of the patients across both cohorts resided in the South U.S. Census division (38.8\% vs. 38.9\%) and were covered by commercial insurance ( $97.2 \%$ vs. $94.1 \%$; $P<0.001)$. Patients in the UQ cohort had significantly greater morbidity than those in the non-UQ cohort, as reflected by a higher mean DCI score (0.61 vs. 0.16; $P<0.001)$, and had a higher percentage of patients with general comorbid conditions. More than half of the study patients were treated with acute medications only, while $17.8 \%$ of patients in the non-UQ cohort and $13.6 \%$ of patients in the UQ cohort received neither acute nor prophylactic treatments. The UQ cohort had a higher proportion of patients with neurologist visits $(30.0 \%$ vs. $18.9 \%$; $P<0.001)$ and more than 2 migraine-related ER visits $(2.17 \%$ 


\begin{tabular}{l|rl}
\hline \multicolumn{1}{c}{ TABLE 2 Adjusted Odds Ratio for Factors } \\
$\begin{array}{l}\text { Associated with Upper } \\
\text { Of All-Cause Costs }\end{array}$
\end{tabular}

vs. $0.47 \% ; P<0.001$ ) compared with the non-UQ cohort. In addition, the number of triptan and opioid prescription claims differed significantly between the 2 cohorts (Table 1).

\section{Factors Associated with the Upper Quartile of All-Cause Costs}

Multivariate logistic regression showed that after controlling for all other factors, patients with $\geq 2$ migraine-related ER visits in the pre-index period were over twice as likely to be in the UQ cohort (odds ratio $[\mathrm{OR}]=2.13,95 \%$ confidence interval $[\mathrm{CI}]=2.02-2.25 ; \quad P<0.05)$. Similarly, patients who visited neurologists were $33 \%$ more likely to be in the UQ cohort $(\mathrm{OR}=1.33,95 \% \mathrm{CI}=1.31-1.35)$ compared with those who did not. Compared with patients who received neither prophylactic nor acute medications in the pre-index period, those who received prophylactic medications only or acute medications only were less likely to be in the UQ cohort; the trend was reversed for those who received both prophylactic and acute medications. These numbers should be interpreted with caution, since the exact duration of treatment with a given medication is unknown. Compared with nonusers, opioid users had an increased likelihood of being in the UQ cohort as follows: $1-2$ claims $(\mathrm{OR}=1.51,95 \% \mathrm{CI}=1.49-1.54)$, 3-6 claims $(\mathrm{OR}=2.12,95 \% \mathrm{CI}=2.08-2.17)$, and 7 or more claims $(\mathrm{OR}=2.97,95 \% \mathrm{CI}=2.92-3.03$; all $P<0.05)$. Patients with 7 or more triptan claims were almost 1.2 times as likely $(\mathrm{OR}=1.17$, 95\% CI $=1.14-1.19)$ to be in the UQ cohort compared with nonusers, while those with $1-3(\mathrm{OR}=0.81,95 \% \mathrm{CI}=0.80-0.83)$ and 4-6 $(\mathrm{OR}=0.91,95 \% \mathrm{CI}=0.89-0.93)$ triptan claims were $19 \%$ and $9 \%$ less likely to be in the UQ cohort compared with nonusers, respectively (Table 2).

\section{Estimated Incremental All-Cause Costs of Key Factors}

Patients with 2 or more pre-index migraine-related ER visits incurred \$3,125 more total all-cause costs compared with those with less than 2 ER visits $(\$ 13,358$ vs. $\$ 10,233 ; P<0.05)$. Estimated all-cause costs for patients who visited a neurologist in the pre-index period were higher than among those who did not, with an incremental difference of $\$ 1,926$ (\$11,794 vs. $\$ 9,868 ; P<0.05)$. Compared with patients who did not receive prophylactic or acute medications, those who received prophylactic and acute medications incurred \$629 more costs, whereas those with acute medication only or prophylactic medication only incurred $\$ 376$ and $\$ 509$ more costs, respectively (all $P<0.05$ ). The adjusted mean of the all-cause annual costs among patients with no opioid claims was $\$ 8,888$ (95\% $\mathrm{CI}=\$ 8,862-\$ 8,914)$ versus $\$ 15,210(95 \% \mathrm{CI}=\$ 15,113-\$ 15,307)$ for high opioid users, that is, patients with 7 or more opioid claims. The estimated mean of the all-cause costs were lower in patients with no triptan claims $(\$ 10,753,95 \% \mathrm{CI}=\$ 10,717$ $\$ 10,790)$ than those with 7 or more triptan claims $(\$ 11,517$, $95 \% \mathrm{CI}=\$ 11,438-\$ 11,596)$, while cost savings were observed in those with $1-3(\$ 9,422,95 \% \mathrm{CI}=\$ 9,389-\$ 9,455)$ and $4-6$ $(\$ 10,300,95 \% \mathrm{CI}=\$ 10,230-\$ 10,371)$ triptan claims (Table 3).

\section{Subgroup Analyses}

Patients with chronic migraine were also investigated separately. Compared with results from the entire study population, chronic migraineurs had a higher percentage of patients with neurologist visits (3.3\%) and more than 2 migraine-related ER visits (51.8\%), indicating more severe migraine for this subgroup. Similar to the main analyses, the UQ cohort had a higher proportion of patients with neurologist visits (55.17\% vs. 49.38\%; $P<0.001)$ and more than 2 migraine-related ER visits (6.22\% vs. $1.25 \% ; P<0.001)$ compared with the non-UQ cohort. 


\section{TABLE 3 Adjusted Mean All-Cause Costs} by Key Cost Drivers

\begin{tabular}{|c|c|c|}
\hline Number of Claims & $\begin{array}{r}\text { Adjusted } \\
\text { Health } \\
(9 \\
\end{array}$ & $\begin{array}{l}\text { Mean All-Cause } \\
\text { Care Costs } \\
\% \text { CI }), \$\end{array}$ \\
\hline \multicolumn{3}{|l|}{ Opioid claims } \\
\hline 0 & 8,888 & $(8,862-8,914)$ \\
\hline $1-2$ & 10,873 & $(10,827-10,919)$ \\
\hline $3-6$ & 12,995 & $(12,910-13,079)$ \\
\hline $7+$ & 15,210 & $(15,113-15,307)$ \\
\hline \multicolumn{3}{|l|}{ Triptan claims } \\
\hline 0 & 10,753 & $(10,717-10,790)$ \\
\hline $1-3$ & 9,422 & $(9,389-9,455)$ \\
\hline $4-6$ & 10,300 & $(10,230-10,371)$ \\
\hline $7+$ & 11,517 & $(11,438-11,596)$ \\
\hline \multicolumn{3}{|l|}{ Medication use } \\
\hline Prophylactic medication only & 9,845 & $(9,740-9,951)$ \\
\hline Acute medication only & 9,978 & $(9,740-9,951)$ \\
\hline Prophylactic and acute medication & 10,983 & $(10,935-11,031)$ \\
\hline $\begin{array}{l}\text { Neither prophylactic nor acute } \\
\text { medication }\end{array}$ & 10,354 & $(10,289-10,419)$ \\
\hline \multicolumn{3}{|l|}{ Migraine-related ER visits } \\
\hline$\geq 2$ visits & 13,358 & $(13,082-13,639)$ \\
\hline$<2$ visits & 10,233 & $(10,213-10,253)$ \\
\hline \multicolumn{3}{|l|}{ Neurologist visits } \\
\hline Yes & 11,794 & $(11,743-11,845)$ \\
\hline No & 9,868 & $(9,846-9,890)$ \\
\hline
\end{tabular}

\section{Discussion}

Evidence suggests that migraine imposes a substantial burden on patients, families, and society, although migraine is not generally perceived as a serious condition. Given its high prevalence $(12 \%)$ and associated disability, ${ }^{3}$ it is important to characterize patients in the top quartile of costs among insured migraine patients, since retrospective studies to evaluate incremental costs by select, potentially modifiable, factors in realworld clinical practice are limited. This study sought to identify these characteristics, which included higher frequencies of migraine-related ER and neurologist visits, as well as the excessive use of opioids and triptans during the baseline period.

Consistent with previous research, ${ }^{17,18,35,36}$ findings of this study suggest a higher prevalence of migraine among women and patients aged 35-49 years (41.7\%), and patients with migraine often present with a greater number of comorbidities than the general population, which stresses the clinical complexity of this disorder and also adds to the financial burden of the disease. Furthermore, this study adds new information to the current literature on the characteristics of migraine patients with high costs. Patients in the UQ cohort had signifi- cantly higher DCI scores and included a significantly higher percentage of patients with psychiatric and other comorbidities compared with those in the non-UQ cohort, indicating that a greater comorbidity burden was associated with higher costs. In addition, the presence of concomitant psychiatric conditions, general comorbid conditions, and acute medication (opioid use and triptan overuse) use also affected all-cause costs.

While neurologist visits are likely indicative of greater disease severity, reducing excessive acute medication use and migraine-related ER visits represent potentially modifiable factors that could be an avenue for reducing costs and improving quality of care for patients with migraine. A recent preliminary study showed that only half of patients who experienced migraine-related symptoms would meet the migraine diagnostic criteria ${ }^{37}$; thus, the associated high costs are potentially because of more severe migraine-related symptoms among those patients who visited a neurologist, not a result of neurologist visits. Although data on severity measures were unavailable in our study sample, we found that $40.2 \%$ of patients who visited a neurologist used more acute and prophylactic medications, further suggesting that these patients may have had frequent attacks and, as a result, may need more appropriate and aggressive disease management. ${ }^{38}$

This study also found that greater use of acute medications and opioids was strongly associated with being in the UQ cohort. However, opioids are neither recommended nor approved for migraine relief and they can be addictive. ${ }^{23,39}$ The pre-index number of opioid claims in this study suggests possible overuse of opioids. Such excessive use of opioids in migraine patients has become a concern because of the potential for abuse and worsening of the disease, which may lead to headaches from medication overuse and poor long-term outcomes. ${ }^{39-41}$ Moreover, patients who overuse opioids are at a high risk of misusing the opioids, and this contributes to inefficiency in health care resource utilization..$^{23,39}$ Triptans are generally recommended for acute treatment of migraine. ${ }^{15,42,43}$ Although they are usually safe, taking triptans too often can also result in headaches from medication overuse. ${ }^{44}$ Future studies are warranted to evaluate the long-term effects of such medications on economic burden and disease management of migraine patients.

\section{Limitations}

This study has several limitations that are associated with retrospective studies using administrative claims. Administrative claims data are collected for the purpose of facilitating payment for medical services and lack clinical specificity found in medical records and physician notes. Clinical markers for assessing severity measures are not captured in claims data. It is worthwhile to evaluate the effect of disease severity on health resource utilization and costs using survey or medical 
record data in future studies. The identification of the migraine population relied on diagnosis and treatment codes recorded in medical and pharmacy claims, which are limited by completeness and accuracy of medical coding. As with any claims databases, costs represented in these data reflect payer and patient costs and reflect the paid amounts of adjudicated claims to individual hospitals and providers but ignore indirect costs or potential caregiver burden. Finally, this study was composed of patients covered by commercial or Medicare supplemental insurance; therefore, the results may not be generalizable to migraine patients with other insurances or those without health insurance coverage.

\section{Conclusions}

In a real-world setting, migraine patients with opioid use, triptan overuse, frequent migraine-related ER visits, and neurologist visits in the pre-index period incurred higher allcause health care costs. Factors such as neurologist visits may indicate greater disease severity. Opioid use was common, and its use characteristics suggest potential overuse. These findings identify factors that could potentially be used to classify patients who have been suboptimally managed and who may benefit from closer monitoring, since they are otherwise likely to incur high financial costs. Further development and implementation of strategies that maximize efficient care for these patients are needed, including more effective preventive care.

\section{Authors}

MACHAON BONAFEDE, PhD, MPH; QIAN CAI, MS, MSPH; KATHERINE CAPPELL, PhD; and GILWAN KIM, PharmD, MS, Truven Health Analytics, Cambridge, Massachusetts. SANDHYA J. SAPRA, PhD; NEEL SHAH, PhD; KATHERINE WIDNELL, MD, PhD; and POOJA DESAI, PhD, Amgen, Thousand Oaks, California. PAUL WINNER, PhD, Premiere Research Institute and Palm Beach Headache Center, West Palm Beach, Florida, and Nova Southeastern University, Fort Lauderdale, Florida.

AUTHOR CORRESPONDENCE: Machaon Bonafede, PhD, MPH, Truven Health Analytics, 75 Binney St., 4th Fl., Cambridge, MA 02140. Tel.: 603.580.5587; E-mail: mbonafed@us.ibm.com.

\section{DISCLOSURES}

This study was funded by Amgen and conducted by Truven Health Analytics. Bonafede, Cappell, and Kim are employees of Truven Health Analytics, which received compensation from Amgen for the overall conduct of the study and preparation of the manuscript. Cai was an employee of Truven Health Analytics at the time of this study. Sapra, Shah, and Desai are employees of Amgen. Katherine Widnell was an employee of Amgen when the manuscript draft was developed. Winner reports receiving research support from Allergan, Amgen, A-Z, Teva, Pfizer, Novartis, and Lilly.
Study concept and design were contributed by Bonafede, Sapra, Shah, and Desai, along with Widnell and Winner. Kim and Cai took the lead in data collection, assisted by Bonafede and Cappell. Data interpretation was performed by Widnell and Winter, along with the other authors. All authors contributed to the writing and revision of the manuscript.

\section{ACKNOWLEDGMENTS}

Editorial/writing assistance for this manuscript was provided by Santosh Tiwari who is an employee of Truven Health Analytics.

\section{REFERENCES}

1. Loder E, Burch R, Rizzoli P. The 2012 AHS/AAN guidelines for prevention of episodic migraine: a summary and comparison with other recent clinical practice guidelines. Headache. 2012;52(6):930-45.

2. Headache Classification Committee of the International Headache Society. The International Classification of Headache Disorders (beta version). Cephalalgia. 2013;33(9):629-808.

3. Migraine Research Foundation. Migraine facts. Available at: http://www. migraineresearchfoundation.org/fact-sheet.html. Accessed September 13, 2017.

4. Schwedt TJ, Vargas B. Neurostimulation for treatment of migraine and cluster headache. Pain Med. 2015;16(9):1827-34

5. Lipton RB, Bigal ME. Migraine: epidemiology, impact, and risk factors for progression. Headache. 2005;45(Suppl 1):S3-S13.

6. Diener HC, Kaube H, Limmroth V. A practical guide to the management and prevention of migraine. Drugs. 1998;56(5):811-24.

7. Gilmore B, Michael M. Treatment of acute migraine headache. Am Fam Physician. 2011;83(3):271-80

8. Miller S. The acute and preventative treatment of episodic migraine. Annals Indian Acad Neurol. 2012;15(Suppl 1):S33-S39.

9. Estemalik E, Tepper S. Preventive treatment in migraine and the new U.S. guidelines. Neuropsychiatr Dis Treat. 2013;9:709-20. Available at: https://www. ncbi.nlm.nih.gov/pmc/articles/PMC3663475/. Accessed September 27, 2017.

10. Silberstein S, Holland S, Freitag F, et al. Evidence-based guideline update: pharmacologic treatment for episodic migraine prevention in adults: report of the Quality Standards Subcommittee of the American Academy of Neurology and the American Headache Society. Neurol. 2012;78(17):1337-45.

11. Cauchi M, Robertson N. CGRP and migraine. J Neurol. 2016;263(1):192-94.

12. Holland S, Fanning KM, Serrano D, Buse DC, Reed ML, Lipton RB. Rates and reasons for discontinuation of triptans and opioids in episodic migraine: results from the American Migraine Prevalence and Prevention (AMPP) study. J Neurol Sci. 2013;326(1):10-17.

13. Wells RE, Markowitz SY, Baron EP, et al. Identifying the factors underlying discontinuation of triptans. Headache. 2014;54(2):278-89.

14. Seng EK, Rains JA, Nicholson RA, Lipton RB. Improving medication adherence in migraine treatment. Curr Pain Headache Rep. 2015;19(6):24.

15. Etemad LR, Yang W, Globe D, Barlev A, Johnson KA. Costs and utilization of triptan users who receive drug prophylaxis for migraine versus triptan users who do not receive drug prophylaxis. J Manag Care Pharm. 2005;11(2):137-44. Available at: http://www.jmcp.org/doi/10.18553/ jmcp.2005.11.2.137.

16. Goldberg LD. The cost of migraine and its treatment. Am J Manag Care. 2005;11(2 Suppl):S62-S67.

17. Lipton RB, Stewart WF, Scher AI. Epidemiology and economic impact of migraine. Curr Med Res Opin. 2001;17(Suppl 1):S4-S12.

18. Muzina DJ, Chen W, Bowlin SJ. A large pharmacy claims-based descriptive analysis of patients with migraine and associated pharmacologic treatment patterns. Neuropsychiatr Dis Treat. 2011;7:663-72. 
19. Rothrock JF, Bloudek LM, Houle TT, Andress-Rothrock D, Varon SF Real-world economic impact of onabotulinumtoxinA in patients with chronic migraine. Headache. 2014;54(10):1565-73.

20. Stokes M, Becker WJ, Lipton RB, et al. Cost of health care among patients with chronic and episodic migraine in Canada and the USA: results from the International Burden of Migraine Study (IBMS). Headache. 2011;51(7):1058-77.

21. Burch RC, Loder S, Loder E, Smitherman TA. The prevalence and burden of migraine and severe headache in the United States: updated statistics from government health surveillance studies. Headache. 2015;55(1):21-34.

22. Niska R, Bhuiya F, Xu J. National Hospital Ambulatory Medical Care Survey: 2007 emergency department summary. Natl Health Stat Rep. 2010;26(26):1-31.

23. Tepper SJ. Opioids should not be used in migraine. Headache. 2012;52(Suppl 1):30-34

24. Vinson DR, Hurtado TR, Vandenberg JT, Banwart L. Variations among emergency departments in the treatment of benign headache. Annals Emer Med. 2003;4l(1):90-97.

25. Tornabene SV, Deutsch R, Davis DP, Chan TC, Vilke GM. Evaluating the use and timing of opioids for the treatment of migraine headaches in the emergency department. J Emer Med. 2009;36(4):333-37.

26. Messali A, Sanderson JC, Blumenfeld AM, et al. Direct and indirect costs of chronic and episodic migraine in the United States: a web-based survey. Headache. 2016;56(2):306-22

27. Hu XH, Markson LE, Lipton RB, Stewart WF, Berger ML. Burden of migraine in the United States: disability and economic costs. Arch Int Med. 1999;159(8):813-18

28. Hawkins K, Wang S, Rupnow M. Direct cost burden among insured U.S employees with migraine. Headache. 2008;48(4):553-63.

29. Shei A, Rice JB, Kirson NY, et al. Characteristics of high-cost patients diagnosed with opioid abuse. J Manag Care Spec Pharm. 2015;21(10):902-12. Available at: http://www.jmcp.org/doi/10.18553/jmcp.2015.21.10.902.

30. Elston Lafata J, Moon C, Leotta C, Kolodner K, Poisson L, Lipton RB. The medical care utilization and costs associated with migraine headache. J Gen Int Med. 2004;19(10):1005-12

31. Noxon V, Lu K, Wu J. Triptan use and associated health care utilization and costs in adults with migraines. Value Health. 2014;17(3):A65 [Abstract]. Available at: http://www.valueinhealthjournal.com/article/S10983015(14)00432-X/abstract. Accessed September 13, 2017.
32. Silberstein SD, Winner PK, Chmiel JJ. Migraine preventive medication reduces resource utilization. Headache. 2003;43(3):171-78.

33. Wu J, Hughes MD, Hudson MF, Wagner PJ. Antimigraine medication use and associated health care costs in employed patients. J Headache Pain. 2012;13(2):121-27.

34. Deyo RA, Cherkin DC, Ciol MA. Adapting a clinical comorbidity index for use with ICD-9-CM administrative databases. J Clin Epidemiol. 1992;45(6):613-19.

35. Breslau N, Lipton RB, Stewart WF, Schultz LR, Welch KM. Comorbidity of migraine and depression: investigating potential etiology and prognosis. Neurology. 2003;6(8):1308-12.

36. Lipton RB, Diamond S, Reed M, Diamond ML, Stewart WF. Migraine diagnosis and treatment: results from the American Migraine Study II. Headache. 2001;41(7):638-45.

37. Scher AI, Wang S, Katsarava Z, et al. Epidemiology of migraine in men: results from the Chronic Migraine Epidemiology and Outcomes (CaMEO) Study. Headache. 2016;56 (Supp 1):6 [Abstract OR08]. Available at: http://online library.wiley.com/doi/10.1111/head.12832/full. Accessed September 27, 2017.

38. Stone J, Carson A, Duncan R, et al. Who is referred to neurology clinics? - the diagnoses made in 3781 new patients. Clin Neurol Neurosurg. 2010;112(9):747-51.

39. Casucci G, Cevoli S. Controversies in migraine treatment: opioids should be avoided. Neurol Sci. 2013;34(1):125-28.

40. Colman I, Rothney A, Wright S, Zilkalns B, Rowe B. Use of narcotic analgesics in the emergency department treatment of migraine headache. Neurol. 2004;62(10):1695-700.

41. Friedman BW, Grosberg BM. Diagnosis and management of the primary headache disorders in the emergency department setting. Emer Med Clin North Am. 2009;27(1):71-87.

42. Messali A, Owens G, Bloudek L, Kori S, Cole A, Chia J. Health care resource utilization following initiation of a triptan: a retrospective claims analysis. J Manag Care Spec Pharm. 2014:20(4):368-75. Available at: http:// www.jmcp.org/doi/10.18553/jmcp.2014.20.4.368.

43. Wu J, Noxon V, Lu ZK. Patterns of use and health expenses associated with triptans among adults with migraines. Clin J Pain. 2015;31(8):673-79.

44. Negro A, Martelletti P. Chronic migraine plus medication overuse headache: two entities or not? J Headache Pain. 2011;12(6):593-601. 